\title{
Variação da cor e propriedades cerâmicas com o aumento da temperatura de queima de uma argila proveniente da formação Corumbataí, região de Piracicaba, SP)
}

\author{
Variation of color and ceramic properties with \\ the increase of temperature of clay's firing from the \\ Corumbatai formation, region of Piracicaba, SP
}

\author{
C. D. Roveri, A. Zanardo, M. M. T. Moreno \\ Departamento de Petrologia e Metalogenia, Instituto de Geociências e Ciências Exatas \\ Universidade Estadual Paulista "Júlio de Mesquita Filho", UNESP - Campus de Rio Claro \\ Av. 24A, 1515, Bairro Bela Vista, C.P. 178, Rio Claro, SP 13506-900 \\ cdroveri@rc.unesp.br,azanardo@rc.unesp.br,mmoreno@rc.unesp.br
}

\begin{abstract}
Resumo
Objetivando compreender a influência do ferro contido na illita, presente na formação Corumbataí, na cor de queima de produtos cerâmicos selecionou-se uma amostra de cor cinza esverdeado claro, dominantemente illítica e com porcentagem de óxidos e hidróxidos de ferro relativamente baixo, com base em estudos petrográficos, mineralógicos e químicos. Para os testes cerâmicos, os corpos de prova foram queimados em forno de queima rápida de laboratório nas temperaturas de $900{ }^{\circ} \mathrm{C}, 950{ }^{\circ} \mathrm{C}, 1000{ }^{\circ} \mathrm{C}, 1050{ }^{\circ} \mathrm{C}$, $1075^{\circ} \mathrm{C}$ e $1100{ }^{\circ} \mathrm{C}$, com taxa de aquecimento de $40^{\circ} \mathrm{C} / \mathrm{min}$, sendo um conjunto de corpos de prova queimado a $950{ }^{\circ} \mathrm{C}$, porém com taxa de aquecimento de $20^{\circ} \mathrm{C} / \mathrm{min}$, com o intuito de verificar a influência do tempo de queima na coloração das peças cerâmicas. $\mathrm{O}$ tempo de queima mostrou não interferir significativamente na alteração da cor e os corpos de prova apenas apresentaram alterações significativas a partir da temperatura de $1000{ }^{\circ} \mathrm{C}$, adquirindo, respectivamente os matizes: laranja, vermelho e marrom escuro. A mudança de cor foi acompanhada em intensidade equivalente pela retração linear de queima, pela absorção de água e módulo de ruptura por flexão.
\end{abstract}

Palavras-chave: argila, mineralogia, cerâmica.

Abstract

The objective of this paper is to understand the influence of the iron contained in the illite, present in the Corumbatai formation, in the color of firing of ceramic products. A sample was selected, with a gray color clearly, with illite domination, hydroxide and oxide percentage and relatively low iron, with basis of petrographics, mineralogical and chemical studies. For the ceramic essays, the test bodies were fired in a fast firing kiln of laboratory in the temperatures of $900{ }^{\circ} \mathrm{C}, 950{ }^{\circ} \mathrm{C}, 1000{ }^{\circ} \mathrm{C}, 1050{ }^{\circ} \mathrm{C}, 1075{ }^{\circ} \mathrm{C}$ and $1100{ }^{\circ} \mathrm{C}$, with heating rate of $40^{\circ} \mathrm{C} / \mathrm{min}$, a set of bodies test was fired at $950{ }^{\circ} \mathrm{C}$, however with heating rate of $20^{\circ} \mathrm{C} / \mathrm{min}$, for the checking of the influence of the time of firing range in the coloration of the ceramic plates. The time of firing range showed not to intervene significantly in the alteration of the color and the test bodies produced significant alterations in the temperature of $1000^{\circ} \mathrm{C}$, acquiring, respectively the shades: orange, red and dark brown. The color change was followed in intensity equivalent for the linear retraction of firing, for the water's absorption and mechanical strength.

Keywords: clay, mineralogy, ceramics.

\section{INTRODUÇÃO}

Os argilitos provenientes da formação Corumbataí abastecem quase que a totalidade das indústrias integrantes do Pólo Cerâmico de Santa Gertrudes, SP. O referido arranjo produtivo local é responsável por cerca de $50 \%$ da fabricação nacional de pisos e revestimentos cerâmicos e vem buscando espaço no mercado internacional.

A formação Corumbataí é uma unidade litoestratigráfica da Bacia do Paraná, de idade permiana, descrita com base em exposições no vale do rio Corumbataí, com espessura máxima da ordem de 130 metros na região de Rio Claro, SP, composta predominantemente por sedimentos argilosos de coloração arroxeada ou avermelhada, com intercalações de lentes de arenitos muito finos [1]. Esta unidade corresponde ao prolongamento, para norte/nordeste das formações Teresina e Rio do Rastro [2], aflorando no estado de S. Paulo ao norte do rio Tietê, com adelgaçamento da espessura para norte, apresentando espessuras da ordem de 60 metros nas imediações de Leme e Pirassununga e desaparecendo nas 
proximidades do limite com o estado de Minas Gerais, na região de Mococa [1].

O material explotado normalmente possui como constituinte maior a illita, seguida por feldspatos (autígenos e detríticos), quartzo, óxidos e hidróxidos de ferro, outros argilominerais (clorita, montmorillonitas, caulinita, biotita, interestratificados regulares e irregulares e muscovita), carbonatos, zeólitas, entre outros minerais [3]. Segundo Souza Santos [4] as argilas da formação Corumbataí seriam classificadas como "sedimentary clay" a "calcareous clay", em função do valor variável de carbonatos encontrados nos diversos estratos.

As peças cerâmicas constituídas por esse material apresentam cor de queima avermelhada a chocolate, aspecto atribuído à significativa presença dos óxidos e hidróxidos de ferro, como hematita e goethita, que em média perfazer pouco mais de $5 \%$ do peso.

O objetivo deste trabalho foi caracterizar o comportamento de uma argila, proveniente dos arredores da cidade de Piracicaba, SP, do ponto de vista químico-mineralógico e físico, avaliando as propriedades cerâmicas do material em diferentes temperaturas, com o intuito de determinar se o ferro, contido na illita, influenciará a coloração de queima e demais propriedades cerâmicas dos pisos e revestimentos produzidos na região.

\section{PROCEDIMENTO EXPERIMENTAL}

Coletou-se, em campo, amostra de rocha bruta, em ponto de coordenadas UTM, Datum Córrego Alegre, 26528,5 N e 7492541,8 E, localizado nas proximidades da Rodovia Piracicaba-Limeira. Dos diversos fragmentos que constituíam a amostra selecionou-se um, através de análise macroscópica (o mais representativo do conjunto), para a confecção de uma seção delgada objetivando a análise microscópica. Posteriormente, efetuou-se a fragmentação primária da amostra em britador de mandíbulas e a moagem em moinho de martelos, até granulometria passante na peneira ABNT 35 (abertura de $500 \mu \mathrm{m}$ ).

Com o material moído e adequadamente homogeneizado tomaram-se alíquotas para a realização da análise química e mineralógica. A análise química foi realizada por fluorescência de raios $\mathrm{X}$, em aparelho Phillips modelo PW 2510, pertencente ao LABOGEO-DPM-UNESP, pela metodologia de fusão, seguindo a metodologia adotada pelo laboratório [5]. A análise mineralógica foi realizada em equipamento D5000 Siemens, medida com radiação Co (comprimento de onda $1,7893 \AA$ ), passo de $0,05^{\circ}$ e tempo de exposição de $0,8 \mathrm{~s}$ por passo e interpretadas com o software EVA 2.0.

A análise petrográfica foi feita em microscópio óptico de marca Leitz, com aumento máximo de 630 vezes. As imagens foram capturadas em microscópio Leica, com uso do software Q-Win. Foi feita a determinação da proporção volumétrica de cada mineral através de contagem em seção delgada.

Como intuito de obter corpos de prova para analisar as propriedades cerâmicas, a argila foi granulada com teor de água de $8,5 \%$ e estocada em embalagens plásticas, por $24 \mathrm{~h}$ para homogeneização da umidade. Posteriormente foram obtidos corpos de prova de dimensões $6 \times 2 \times$ $0,75 \mathrm{~cm}^{3}$, utilizando pressão de $215 \mathrm{kgf} / \mathrm{cm}^{2}$ (densidade geométrica média a seco $1,91 \mathrm{~g} / \mathrm{cm}^{3}$ ), em prensa manual de laboratório, que, posteriormente, foram secos em estufa elétrica por $24 \mathrm{~h}$ a $100^{\circ} \mathrm{C}$.

As queimas foram feitas em forno de queima rápida Maitec a $900{ }^{\circ} \mathrm{C}, 950{ }^{\circ} \mathrm{C}, 1000{ }^{\circ} \mathrm{C}, 1050{ }^{\circ} \mathrm{C}, 1075{ }^{\circ} \mathrm{C}$ e $1100{ }^{\circ} \mathrm{C}$ com taxa de aquecimento $40{ }^{\circ} \mathrm{C} / \mathrm{min}$. Realizou-se ainda nova queima a $950{ }^{\circ} \mathrm{C}$, porém com taxa de aquecimento de $20{ }^{\circ} \mathrm{C} / \mathrm{min}$ para verificar a influência da velocidade de queima na coloração das peças cerâmicas.

Com os corpos de prova foram realizados ensaios de módulo de ruptura a flexão a seco, absorção de água, retração linear pós queima e módulo de ruptura a flexão pós queima.

\section{RESULTADOS E DISCUSSÃO}

São apresentados os resultados das análises petrográficas, de difração e fluorescência de raios $\mathrm{X}$ e dos ensaios cerâmicos.

Petrografia: Macroscopicamente a rocha em foco apresenta cor cinza esverdeado claro com leve matiz amarelado, textura lutítica (presença de argilominerais em grande quantidade, com granulometria dominante silte fino, 4 a $6 \mu \mathrm{m}$ ) e estrutura anisotrópica e homogeneidade estrutural e textural, falta de bandamento e aspecto que aliado

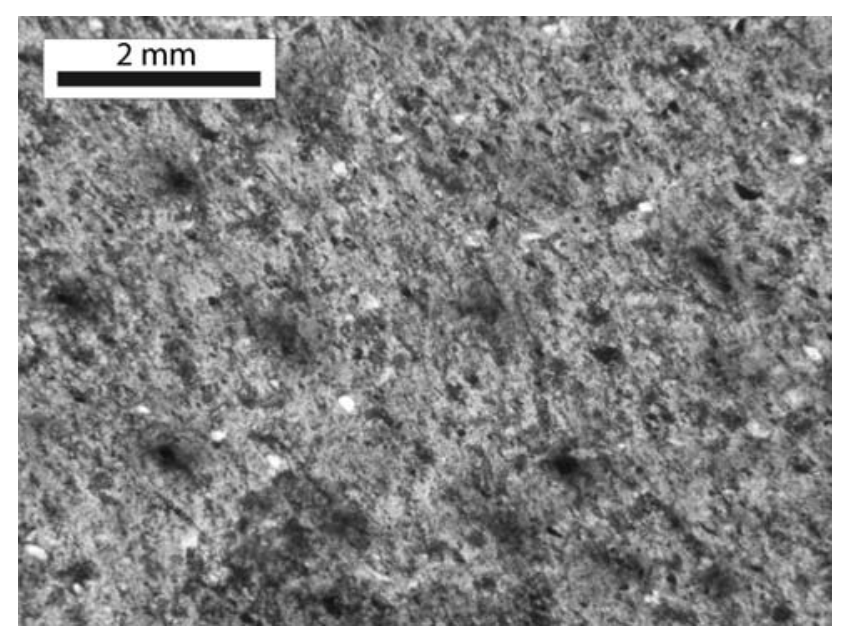

Figura 1: Fotomicrografia mostrando uma "massa" composta dominantemente por cristais de illita orientados envolvendo grãos clásticos de quartzo e feldspato (grãos cinza), palhetas de micas e máculas formadas por películas intersticiais de óxidos/hidróxidos, normalmente com hematita ou magnetita no centro.

[Figure 1: Photomicrograph showing a "mass" composed dominant for oriented crystals of illite involving clastic grains of quartz and feldspar (gray grains), vanes of muscovite and spots formed by interstitial hydroxide and oxide films, normally with hematite or magnetite in the center. Polars crossed and scales in the right superior portion of the image.] 
à granulometria muito fina gera aspecto maciço, não ficando evidente a orientação dos constituintes sem uso de lupa ou microscópio. Com auxílio de lupa manual com aumento de 20 vezes foi possível reconhecer algumas palhetas de mica com dimensões submilimétricas e minúsculos clastos granulares envoltos por uma massa afanítica (minerais que não são visíveis a olho nu ou lupa com até $20 \mathrm{x}$ de aumento).

Ao microscópio observou-se boa orientação dos filossilicatos gerando textura com aspecto de clivagem ardosiana e estrutura sutilmente laminada/bandada, com clastos de quartzo e feldspatos exibindobaixo arredondamento e esfericidade, e máculas de coloração marrom avermelhado a amarelo-alaranjado. As máculas são geradas por películas intersticiais de óxidos e hidróxidos de ferro, que possuem no centro cristais micrométricos, normalmente menores que 40 $\mu \mathrm{m}$, de óxidos de ferro (hematita e/ou magnetita) (Fig. 1).

A análise microscópica possibilitou determinar que a rocha é composta dominantemente por illita (mais de $65 \%$ ), quartzo e feldspatos detríticos, com predomínio do primeiro $(10 \%$ a $15 \%)$, micas detríticas representadas, em ordem decrescente por muscovita, biotita e clorita (2 a $3 \%$ ), óxidos e hidróxidos de ferro (cerca de 1\%). Além desses minerais, foi possível observar: a presença de minúsculos cristais granulares, com dimensões menores que $5 \mu \mathrm{m}$ dispostos intersticialmente aos cristais de illita, que aparentam serem representados dominantemente por albita (10 a 20\%) e por quartzo (10 a $15 \%)$; filossilicatos de dimensões micrométricas, birrefringência baixa e cor esverdeada que aparentam tratar-se de minerais do grupo da clorita (menos de 5\%); a presença de películas delgadas descontínuas, dispostas ao longo dos planos de acamamento, constituídas por argilo-minerais resultantes de alteração supérgena (minerais do grupo da montmorillonita e/ou interestratificados); fragmentos de restos fósseis (menos de $1 \%)$ e; raros cristais de minerais detríticos pesados.

A illita constitui minúsculas palhetas de coloração levemente esverdeada, com comprimento médio da ordem $5 \mu \mathrm{m}$, sendo que os cristais mais desenvolvidos atingem mais de $10 \mu \mathrm{m}$, chegando a confundir-se com clastos de muscovita. Os clastos terrígenos, excetuando algumas palhetas de micas que atingem comprimento entre $150 \mu \mathrm{m}$ e $200 \mu \mathrm{m}$, apresentam dimensões normalmente inferiores a $100 \mu \mathrm{m}$, com média ao redor de $50 \mu \mathrm{m}$. Encontram-se dispersos mais ou menos homogeneamente pela rocha e chegam a formar trilhas e difusas concentrações lenticulares orientadas segundo o plano de deposição.

Difração de raios $X$ : A análise mineralógica através de difração de raios $X$ (Fig. 2) demonstra que a matéria-prima é formada essencialmente por illita, quartzo, albita, existindo evidências da presença de minerais do grupo da clorita,

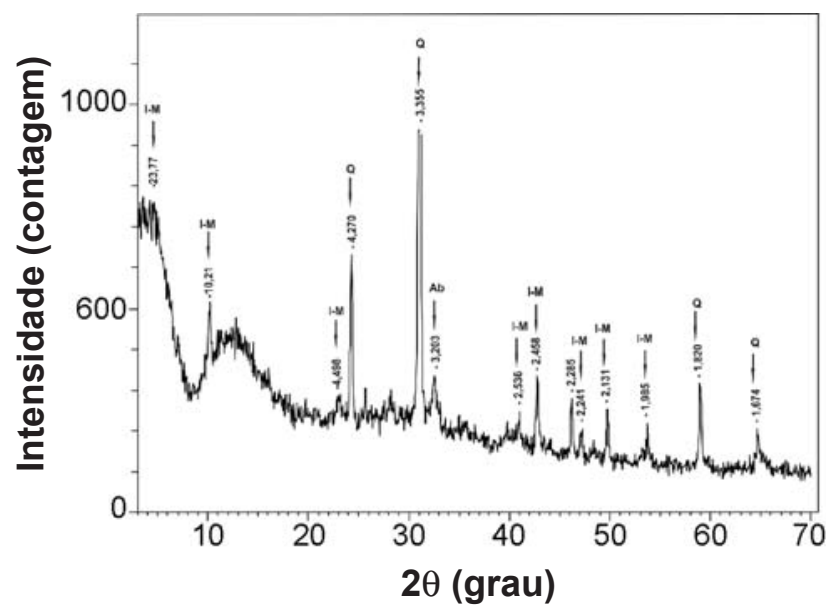

Figura 2: Difratograma de raios X da amostra de rocha. I - M: illitamontmorillonita; Q: quartzo; In-Cl: interestratificados e/ou clorita; Ab: albita.

[Figure 2: X-ray diffration pattern of the of rock sample. I M: illite-montmorillonite; $Q$ : quartz; In-CL: interstrates and/or chlorite; Ab: albite.]

montmorillonita e interestratificados. Não são observados os picos de ocorrência dos minerais de ferro, como hematita, apesar do alto teor de óxido de ferro, relativamente elevado, acusado pela análise química apresentada abaixo. Na escala $2 \theta$, na faixa de 10 a 20 , são observados diversos picos de pequena magnitude. Estes podem relacionar-se a ruídos de leitura ou à presença de interestratificados, minerais do grupo da clorita e/ou da montmorillonita, em porcentagens próximas a $5 \%$.

Composição química: O resultado da análise química, relativo aos elementos maiores, obtido por fluorescência de raios X (Tabela I) está de acordo com a mineralogia determinada e respectivas porcentagens estimadas por microscopia. O teor relativamente elevado de $\mathrm{K}_{2} \mathrm{O}(3,23 \%$ em peso) está de acordo com grande quantidade de illita detectada pelos estudos microscópicos, enquanto que o teor de $\mathrm{Na}_{2} \mathrm{O}(1,46 \%)$ está condizente com o teor de albita aventado pelo estudo microscópico. Por outro lado, a perda ao fogo relativamente baixa (P.F. 2,42\%) condiz com a ausência de carbonatos, aspecto concordante com o baixo teor de $\mathrm{CaO}(0,26 \%)$ e desta forma, o teor de $\mathrm{MgO}$ relativamente alto (2,29\%), resulta da composição da illita e secundariamente da clorita e minerais interestratificados, em função desta última aparecer em diminutas quantidades, como demonstram os estudos ópticos e de difração de raios X.

A porcentagem em peso de ferro total $\left(\mathrm{Fe}_{3} \mathrm{O}_{3}=4,74 \%\right)$, de acordo com os estudos microscópicos, não pode ser explicada pela presença de óxidos/hidróxidos, que ocorrem apenas em

Tabela I: Análise química da argila.

[Table I: Chemical analysis of the clay.]

\begin{tabular}{cccccccccccc}
\hline $\mathrm{SiO}_{2}$ & $\mathrm{TiO}_{2}$ & $\mathrm{Al}_{2} \mathrm{O}_{3}$ & $\mathrm{Fe}_{2} \mathrm{O}_{3}$ & $\mathrm{MnO}$ & $\mathrm{MgO}$ & $\mathrm{CaO}$ & $\mathrm{Na}_{2} \mathrm{O}$ & $\mathrm{K}_{2} \mathrm{O}$ & $\mathrm{P}_{2} \mathrm{O}_{5}$ & P.F. & Soma \\
\hline 72,61 & 0,58 & 12,29 & 4,74 & 0,03 & 2,29 & 0,26 & 1,46 & 3,23 & 0,09 & 2,42 & 100,02 \\
\hline
\end{tabular}


porcentagem volumétrica ao redor de $1 \%$. Na ausência de outras possibilidades, também tem que estar presente na illita e secundariamente na clorita, filossilicatos interestratificados e/ou minerais do grupo da montmorillonita, onde o ferro bivalente $\left(\mathrm{Fe}^{++}\right)$ocorre em solução sólida com o magnésio, em sítios de coordenação octaédrica, gerando coloração esverdeada para estes minerais, explicando a coloração da amostra em questão. Cabe ressaltar que, o $\mathrm{Fe}^{3+}$ também pode estar presente na illita, talvez em quantidade superior ao do $\mathrm{Fe}^{2+}$, nos sítios de coordenação octaédrica, no local do Al.

A estimativa da proporção mineralógica com base na análise química é prejudicada pela complexidade da fórmula química da illita, na qual os sítios de coordenação 12 estão parcialmente preenchidos por potássio, fazendo com que a substituição do Si por Al no tetraedro também seja parcial, além de não ser estimável a substituição do $\mathrm{Al}$ por $\mathrm{Fe}$ e $\mathrm{Mg}$ no octaedro a partir da análise química, em especial pela presença de muscovita, biotita, clorita, interestratificados e/ou minerais do grupo da montmorillonita. Por outro lado a quantificação dessas fases através da microscopia óptica é impossível, em função da granulometria e textura da rocha.

Apesar das incertezas expostas no parágrafo anterior, considera-se que a fase amplamente dominante é a illita, que quartzo e albita aparecem em proporções subordinadas e que as outras fases minerais (feldspatos potássicos detríticos, micas, cloritas e outros filossilicatos) ocorrem em quantidades bem inferiores. Foi possível estimar a partir da análise química, baseando-se em composições químicas minerais contidas em DEER et al. (1966), que a illita deve corresponder a um teor mínimo de $50 \%$ e máximo de $65 \%$, o quartzo de 25 a $30 \%$ e a albita ao redor de $13 \%$. Mesmo considerando os teores mais baixos de illita obtidos por esta estimativa, que aparenta estar subestimando essa fase e superestimando o quartzo, em função dos aspectos colocados acima, a perda ao fogo (P.F.) da análise (Tabela I) está abaixo do estimado. Este fato pode ser explicado pela oxidação do $\mathrm{Fe}^{++}$presente na illita durante a calcinação da amostra por quatro horas a $1000{ }^{\circ} \mathrm{C}$, temperatura em que o $\mathrm{Fe}^{2+}$ começa a ser liberado e oxidado pela atmosfera oxidante da mufla, gerando $\mathrm{Fe}^{3+}\left(\mathrm{Fe}_{2} \mathrm{O}_{3}\right)$.

$\mathrm{O}$ teor relativamente alto de álcalis $\left(\mathrm{Na}_{2} \mathrm{O}+\mathrm{K}_{2} \mathrm{O}=4,69 \%\right.$ e $\mathrm{Mg} 0+\mathrm{CaO}=2,55 \%$ ) em paralelo com o teor de $\mathrm{Al}_{2} \mathrm{O}_{3}$ relativamente baixo $(12,29 \%)$, especialmente considerando as fases minerais presentes, garantem a baixa refratariedade desta argila.

Queimas e ensaios cerâmicos: Os corpos de prova foram queimados em diversas temperaturas $\left(900^{\circ} \mathrm{C}, 950{ }^{\circ} \mathrm{C}\right.$, $1000{ }^{\circ} \mathrm{C}, 1050{ }^{\circ} \mathrm{C}, 1075{ }^{\circ} \mathrm{C}$ e $1100{ }^{\circ} \mathrm{C}$ ), escolhidas com base na temperatura de início de fusão das argilas da formação Corumbataí da região, dominantemente illíticas, com o intuito principal de verificar se ocorre alteração na cor de queima, com o incremento da temperatura, em matéria-prima de cor clara, porém com teor relativamente elevado de ferro.

As massas cerâmicas, oriundas da formação Corumbataí, preparadas pelo processo de via seca, no Polo de Santa Gertrudes, bem como as estudadas pelo Grupo de Pesquisa "Qualidade em Cerâmica" do IGCE/UNESP até o presente

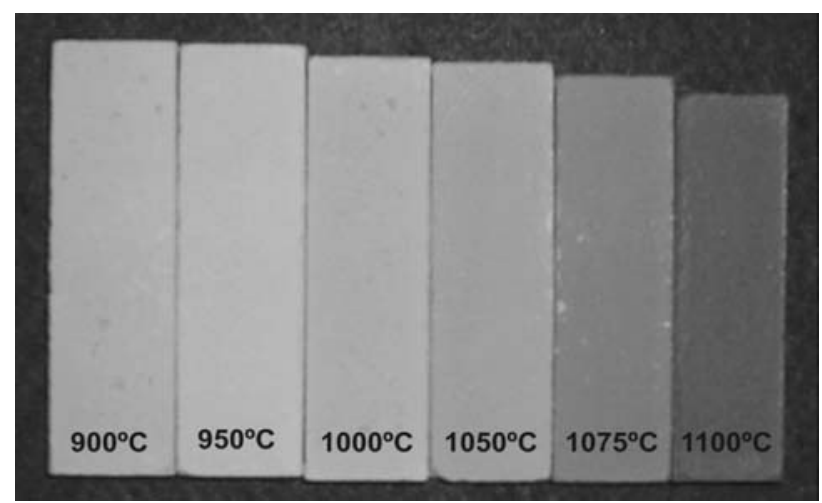

Figura 3: Corpos de provas referentes às queimas realizadas. [Figure 3: Samples after firing.]

momento, são de cor vermelha a arroxeada, com várias tonalidades e matizes e geram cor de queima vermelha a marrom avermelhado escuro, desde os primeiros estágios de sinterização (a partir de $850^{\circ} \mathrm{C}$ ), em função da significativa presença de hematita e/ou goethita, com média pouco superior a $5 \%$.

Os corpos de prova queimados a $900{ }^{\circ} \mathrm{C}$ apresentaram cor idêntica aos não queimados; a $950^{\circ} \mathrm{C}$ perderam o matiz esverdeado, acentuando o matiz amarelo pálido, a $1000{ }^{\circ} \mathrm{C}$ passaram a apresentar coloração amarela alaranjado clara; a $1050{ }^{\circ} \mathrm{C}$ adquiriram cor alaranjada; a $1075^{\circ} \mathrm{C}$ cor vermelha e a $1100{ }^{\circ} \mathrm{C}$ cor marrom escuro (Fig. 3). Nota-se que apenas ocorreu significativa mudança de cor a temperatura superior a $1000{ }^{\circ} \mathrm{C}$, temperatura em que iniciou a liberação de ferro bivalente, que por oxidação passa a ferro trivalente responsável pela cor vermelha. A temperaturas da ordem de $1100{ }^{\circ} \mathrm{C}$, temperatura que começa a ocorrer a super queima o ferro trivalente começa a reduzir gerando a cor marrom avermelhado escuro a preto.

Com o objetivo de verificar a influência do tempo de queima na cor dos corpos de prova foram queimados três deles a $950{ }^{\circ} \mathrm{C}$, com o dobro do tempo, e o resultado foi idêntico, demonstrando que a taxa de aquecimento não

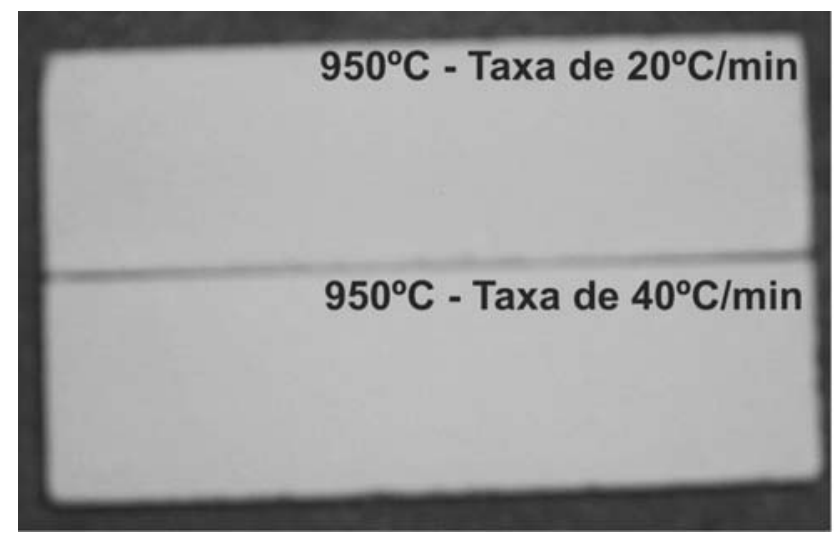

Figura 4: Corpos de prova submetidos a velocidades de queima diferentes.

[Figure 4: Samples submitted to different rates of firing.] 
influencia de forma significativa a cor de queima, pelo menos no caso do forno de laboratório utilizado, sem que ocorra a liberação do ferro da estrutura dos filossilicatos (Fig. 4).

A análise da curva de gresificação (Fig. 5), que se constitui na representação gráfica do comportamento de queima de determinado material, permite a visualização de resultados e acompanhamento da sinterização da matéria-prima em questão. O gráfico possibilita visualizar que a sinterização inicia-se de forma efetiva apenas a temperaturas próximas de $1050{ }^{\circ} \mathrm{C}$, uma vez que nas temperaturas inferiores a retração linear de queima é insignificante, a absorção de água alta (superior a 15\%) e a resistência à flexão baixa (Fig. 6). A partir de $1050{ }^{\circ} \mathrm{C}$ a retração linear de queima (RLQ) aumenta rapidamente de valores da ordem de 1,2\% a $6,2 \%$ (temperatura de queima $1075^{\circ} \mathrm{C}$ ) e $6,8 \%$ (a $1100{ }^{\circ} \mathrm{C}$ ). Esta retração é acompanhada de correspondente diminuição da porosidade aberta, refletida na rápida diminuição da absorção de água, chegando ao redor de $1 \%$ à temperatura de $1100^{\circ} \mathrm{C}$. A sinterização com a formação de fase líquida aparenta ocorrer apenas a temperaturas superiores a $1050^{\circ} \mathrm{C}$, quando ocorre a expressiva diminuição da absorção de água, pelo preenchimento dos poros e aumento da retração linear de queima, pela aproximação das partículas.

A cor de queima clara a temperaturas inferiores a $1050^{\circ} \mathrm{Ce}$ tempos de queima inferiores a três horas, associada à absorção de água inferior a $20 \%$, correspondem a revestimentos porosos de classe BIII, de acordo as especificações propostas na norma ISO 13818. Todavia, o grau de sinterização é muito baixo a estas temperaturas, resultando em baixa resistência mecânica, inviabilizando seu uso para a fabricação de telhas e outros produtos estruturais sem mistura com outra matériaprima que possibilite uma maior resistência mecânica entre $900{ }^{\circ} \mathrm{C}$ e $1050{ }^{\circ} \mathrm{C}$.

A resistência mecânica à flexão apresentada pelos corpos de prova queimados nas diferentes temperaturas está na Fig. 6, que também contém o valor médio obtido para o módulo de ruptura a flexão a seco a $100{ }^{\circ} \mathrm{C}$, da argila que é de 5,08 $\mathrm{MPa}$ (aproximadamente $51 \mathrm{kgf} / \mathrm{cm}^{2}$ ).

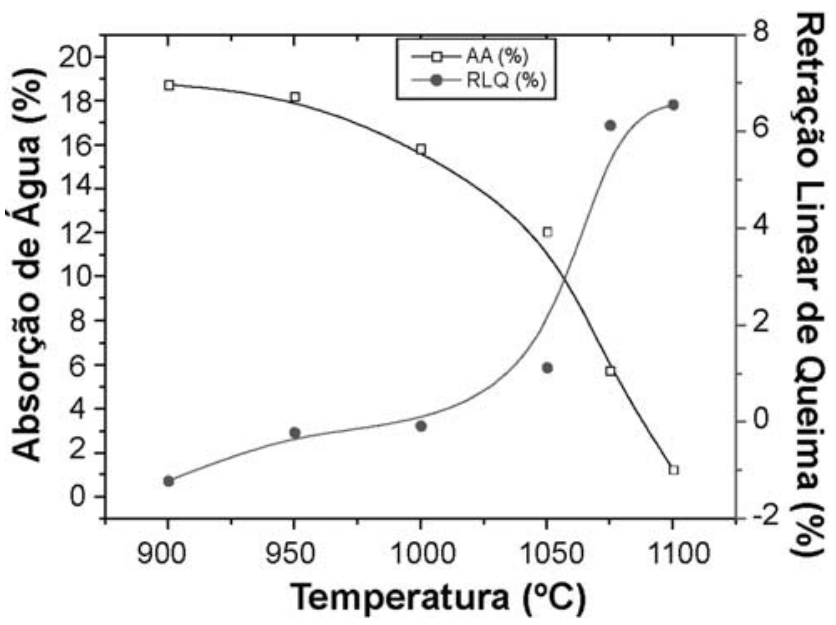

Figura 5: Curva de gresificação da argila. Figure 5: Sintering curve of the clay.
Os corpos queimados a $900{ }^{\circ} \mathrm{C}$ e $950{ }^{\circ} \mathrm{C}$ apresentaram resistência semelhantes (cerca de $9,0 \mathrm{MPa}$ ), portanto pouco superior ao corpo seco, demonstrando que não houve sinterização. Esta propriedade mostra que a sinterização começou por volta de $1000{ }^{\circ} \mathrm{C}$, temperatura que reações químicas relativas à illita ou metaillita possibilitam o início de reação de sinterização, aparentemente sem envolvimento de fase de fusão.

As análises térmicas de matérias-primas dominantemente illíticas, em congruência com resultados de illitas existentes na literatura [6], mostram que a desestruturação da illita começa por volta de $530{ }^{\circ} \mathrm{C}$, porém os resultados obtidos mostram que somente ao redor de $1000{ }^{\circ} \mathrm{C}$ o produto da quebra da illita possibilita a sinterização ao mesmo tempo que ocorre a liberação de $\mathrm{Fe}^{2+}$. A partir dessa temperatura a resistência aumenta rapidamente e por volta de $1050{ }^{\circ} \mathrm{C}$, ocorre o início de formação de fase líquida. Acima de $1075^{\circ} \mathrm{C}$ o material apresenta os valores mais elevados de resistência mecânica, em consonância com a absorção de água e retração linear de queima. Desta forma, como já era esperado, observase boa correlação entre a resistência mecânica pós queima com a sinterização discutida acima.

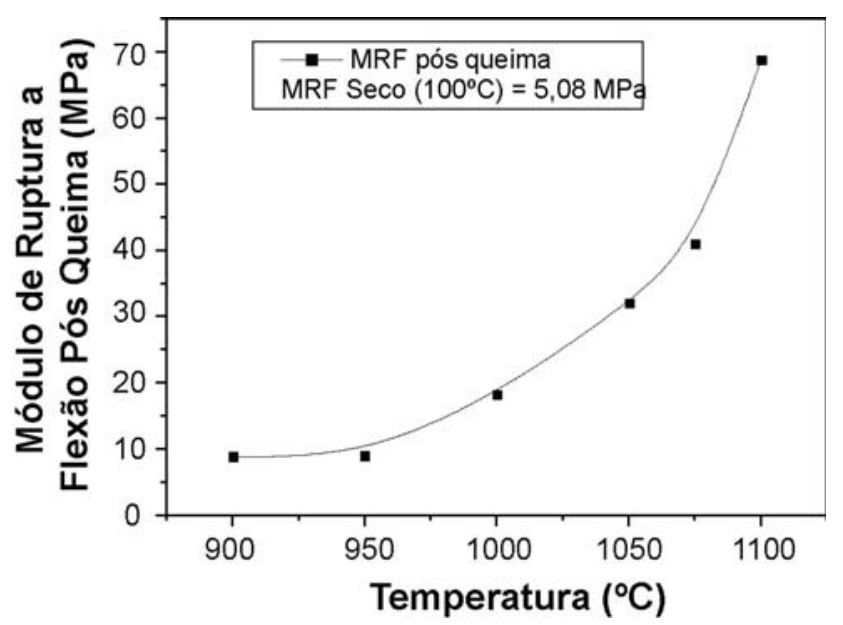

Figura 6: Módulo de ruptura a flexão pós-queima. [Figure 6: Mechanical strength after firing]

\section{CONCLUSÕES}

Com base nos procedimentos realizados pode-se concluir que:

- a argila em estudo apresenta comportamento diferenciado frente às variações na temperatura e velocidade de queima, quando comparada a outros materiais, provenientes da mesma formação geológica (formação Corumbataí). As principais diferenças estariam relacionadas à natureza da illita, uma vez que este mineral apresenta quimismo bastante complexo e a forma de ocorrência do ferro, ocorrendo, nesta argila, em sua estrutura e não como óxidos e hidróxidos livres.

- a análise petrográfica mostrou-se uma ferramenta eficiente na determinação de parâmetros relativos à 
normalização mineral (cálculos de fases minerais com base nos resultados químico-mineralógicos).

- a sinterização tem início a $1000{ }^{\circ} \mathrm{C}$, quando material proveniente da illita, fase dominante, atinge atividade suficiente para tal, sem a participação das fases líquidas. Estas passam a desenvolver-se em temperaturas superiores a $1050{ }^{\circ} \mathrm{C}$.

- a mudança de coloração nos corpos de prova está relacionada à liberação de $\mathrm{Fe}^{2+}$ presente na illita, por volta de $1000{ }^{\circ} \mathrm{C}$, conferindo a estes, coloração que varia de laranja a avermelhada. Assim, a influência do ferro é verificada acima desta temperatura.

- para a determinação do potencial tecnológico das matérias-primas deve-se correlacionar suas propriedades químico-mineralógicas às cerâmicas, sempre buscando a adequação às normas vigentes.

- para utilizar-se a argila em estudo para a fabricação de telhas e outros produtos estruturais deve-se realizar a formulação por meio de mistura com outra matéria-prima que possibilite uma maior resistência mecânica entre $900^{\circ} \mathrm{C}$ e $1050{ }^{\circ} \mathrm{C}$ ou aumentar significantemente o tempo de queima.

\section{AGRADECIMENTOS}

À FAPESP (Processos 03/01123-7 e 2005/036835) e CNPq (Processo 303267/2002-0 e Cota PIBIC 107805/2004-9).

\section{REFERÊNCIAS}

[1] P. M. B. Landim, Boletim Divisão Geologia e Mineralogia/ DNPM, 252, 1 (1970) 1-103.

[2] E. J., Milani, M. L., Assine, P. C. Soares, Boletim de Geociências Petrobrás, V. Especial Bacia do Paraná (1994) 1-200.

[3] A, Zanardo, C. D., Roveri, M. M. T. Moreno, M.R., Masson, E. S., Bernardes, Anais do XLI Congresso Brasileiro de Geologia, Araxá, MG, 1 (2004) p.178.

[4] P. Souza Santos, Tecnologia de argilas aplicada às argilas brasileiras, Ed. Edgard Blucher, S. Paulo, Brasil (1975) p. 200.

[5] A. J. R. Nardy, J. Enzweiler, O. Bahia F., M. A. F. Oliveira, M. A. V. Penereiro, Anais do VI Congresso Brasileiro de Geoquímica, Salvador, BA, 2 (1997) p. 346-348.

[6] J. B. Dixon, Minerals in Soil Enviroments, $2^{\text {nd }}$ Ed., Soil Science Society of America, London (1997) p. 855.

(Rec. 08/01/2007, Rev. 16/04/2007, Ac. 10/08/2007) 